\title{
Classification and manifestation forms of rights and interests of disability trust in China
}

\author{
Ren Jiayang
}

School of Arts and Law, Wuhan University of Technology ,Wuhan, 430070, China

\section{6@qq.com}

\begin{abstract}
In essence, rights and interests of disability trust are to allow the disabled to have equal access to proper and all-around trust services, and to promote sound development of trust institutions. To get a better understanding of rights and interests of disability trust in China relies on in-depth analysis of the classification and manifestation forms of such rights and interests. This paper first classifies rights and interests of disability trust in China in terms of the nature, functions and service providers. Then, specific manifestation forms of rights and interestsof disability trust in China are discussed in terms of social security, daily care and rehabilitation, education and employment, and social participation.By doing so, the author deepens the understanding of connotation of rights and interests of disability trust.
\end{abstract}

Keywords: rights and interests of disability trust; classification; manifestation forms

\section{Classification of Rights and Interests of Disability Trust}

\subsection{In Terms of the Nature}

In terms of the nature, interests and rights of disability trust should include three aspects. Constitution of rights and interests of disability trust is an organic combination of universality and particularity.

First, "Constitution of the People's Republic of China" stipulates that "All persons holding the nationality of the People's Republic of China are citizens of the People's Republic of China. All citizens of the People's of China are before the law. Every citizen enjoys the rights and at the same time must perform the duties prescribed by the Constitution and the law." Therefore, the disabled are also citizens of China.

Second, considering the special situations of the disabled compared with the normal people, the disabled should be ensured for their equal and full participation in social life and their share of the material and cultural wealth of society. "Law of the People's Republic of China on the Protection of the Disabled" clarifies six basic rights and interests of the disabled in terms of rehabilitation, education, employment, cultural life, welfare and environment.

Third, considering specialness of trust services, rights and interests of trust should be pointed out. According to "Notice of China Disabled Persons' Federation on Printing and Issuing Major Documents about Trust Services for the Intelligently and Mentally Disabled", trust services for the disabled should cover not only "care" but also "social development". This justifies rights and interests of the disabled in terms of physical and mental health, educational employment, social life, and receiving formal services from disability trust institutions.

\subsection{In Terms of the Functions}

In terms of the functions, rights and interests of disability trust should include not only rights and interests of enjoying trust services, but also rights and interests of monitoring quality of trust services.

During the trust service process, the disabled are in a vulnerable position both physically and physically. Thus, rights and interests of the mentally disabled, intelligently disabled and seriously physically disabled to get spiritual education, spiritual assistance, judicial relief, monitoring and reporting channels should be guaranteed.

Additionally, many local governments are trying outsourcing disability trust services in the form of "government purchase". In this way, it is all the more necessary for the disabled and family members of the disabled to monitor behaviors of trust institutions and staff. Meanwhile, in order to further standardize development of the disability trust industry, it is imperative to include appeal, feedback and relief channels into rights and interests of disability trust.

\subsection{In Terms of the Counterparts}

In terms of the counterpart, in the other words, service providers, disability trust institutions and their staff should also be entitled to rights and interests of developing the disability trust industry.

"Opinions on Accelerating Development of the Disability Trust Services" points out that the government should provide policy support for disability trust institutions in terms of land, finance, and income tax, and also in terms of real estate taxes, land use taxes and value-added taxes promoting employment of the disabled. Effective protection of rights and interests of disability trust institutions and staff can benefit sound development of disability trust services, which has a close bearing on realization of disability trust rights and 
interests. Staff of disability trust institutions also includes volunteers, whose rights and interests of life safety should also be guaranteed particularly when providing care for the mentally disabled.

\section{Manifestation forms of rights and interests of disability trust}

\subsection{Social Security}

In modern society, it is the duty of the state and the government to provide the social members with as many different forms of welfare and security as possible, especially for disanled members.Currently, most of the disabled in urgent need of disability trust services in Chinese society have lost their basic ability to work and the ability to live a normal social life. Their income is generally at a low and medium level. Some of them are abandoned by their family members or the disabled who have been old and get none to take care of them. They cannot afford the trust services. Some suffering from mental disabilities, intelligence disabilities and serious physical disabilities even have difficulty in applying for trust services independently.

Subsidies and special auxiliary measures are necessary to help realize trust rights and interests of the disabled. Social security can allow the disabled qualified for trust services to have equal access to trust services. All walks of society should encourage and support the disabled in need to apply for trust services to better safeguard their rights and interests of disability trust. Development the social security for disables trust services is not only an important work to ensure the basic life of persons with disabilities, is also doing necessary for social equity and justice.

\subsection{Daily Care and Rehabilitation}

The basic function of disability trust institutions is to provide daily care, nursing and rehabilitation services for the disabled. This is to ensure the disabled can enjoy the right of survival and rehabilitation services as equals. Apart from daily care, disability trust institutions should also arrange necessary daily rehabilitation training to assist the disabled in recovering their basic abilities of daily living and guide the disabled to return to the normal life or even get integrated into the society.

More importantly, disability trust institutions should help the disabled seek mental comfort. Compared with the general disabled persons, the disabled receiving trust services are lacking spiritual and cultural life more seriously. The situation is even worse among those who have been old. On the one hand, their physical conditions are deteriorating, and the likelihood for them to step into the society is decreasing. On the other hand, long-term lack of necessary social care or aging has built stress within the heart of the disabled. Thus, psychological consulting services and outdoor activities are important approaches to improving mental and physical health of the disabled.

\subsection{Education and Employment}

In the broad sense, disability trust services are far beyond daily care and nursing, which actually covers development of all-around social abilities for every disabled person. Different from the general education for the disabled, the education provided by disability trust services is targeted at the disabled who have been at the age group of employment but cannot work. To educated these disabled persons can, on the one hand, guide them to live a normal life, orient their life value, and most importantly guarantee their equal access to education. Onthe other hand, through employment training, a preparatory employment education model such as the sheltered workshop mentioned above can be adopted to realize rights and interests of the disabled.

Meanwhile, standardization of employment training among staff of disability trust institutions is also a key to safeguarding rights and interests of disability trust. As an example, the Chinese government has issued "Basic Standards on Providing Disability Trust Services (Trial)" so as to standardize services of disability trust institutions. Another example of government effort to put development of disability trust services in the right track is the issuance of "Standards on Construction of Disability Trust Service Institutions". Under the trust service model of sheltered employment, staff should not only learn psychological, physical and behavioral characteristics of the disabled, but also learn how to communicate with the disabled and give them help so as to realize sheltered employment of the disabled ${ }^{[1]}$.

\subsection{Social Participation}

"Opinions on Accelerating Development of Disability Trust Services" issued by seven ministries of the People's Republic of China in 2012, clearly states the necessity of allowing the intelligently, mentally and seriously physically disabled to participate in social life as equals and the necessity of reducing the burden of families with disabilities to promote social harmony. In March 2010, the General Office of the StateCouncil forwarded "Guiding Notice on Accelerating Construction of the Social Security System and the Service System"issued by China Disabled Persons'Federation and other departments and units, which stipulates that construction of the disabled persons' service system should be further strengthened, and the disability trust service system should be improved so as to provide better daily care, employment-oriented rehabilitation, 
assisted employment, work therapy, farm therapy, culture and sports, psychological consulting and entertainment services for the mentally, intelligently and seriously physically disabled in accordance with "Opinions of the State Council on Promoting the Undertaking Development for the Disabled."

To lead the disabled to participate in all kinds of cultural, sports and entertainment activities is a critical method to realizing equal participation of the disabled into cultural life. Apart from actively participating in various cultural and social activities, the disabled receiving disability trust services should also be ensured the rights and interests of monitoring and reporting staff working in disability trust institutions. If management or services of disability trust institutions are unreasonable, the disabled and family members of the disabled can report on their behaviors. Since most of the disabled receiving disability trust services are in a vulnerable position and cannot independently play a monitoring role, there should be special appeal and feedback institutions as well as restriction approaches set up to facilitate the implementation of the monitoring right by the disabled. For example, legal assistance can be provided, or the disabled persons' association can visit the disability trust institutions. All this can contribute to realization of the right of monitoring and reporting among the disabled receiving disability trust services.

The integration of disabled people into society requires not only government efforts, but also the power of all roles of society.Goverment should give full spece to the "private" and "common commonalities" of non-profit organizations, let it play an important role in public affairs. The status of non-profit organizations should be established in the form of the law, with a series of policies to encourage the development of non-profit organizations.Also, accelerating the institutionalization of tax work for non-profits, and make clear the terms and conditions for the reduction tax. Grassroots communities should also cooperate with the social integration of the service disabled.For example, Grassroots communities can coordinate with the care organization to organize community activities to help service disabled people integrate into society

\section{Conclusions}

This paper classifies the rights and interests of the disability trust in three aspects: nature, functions and Counterparts. The specific manifestation of the rights and interests of the disabled is four aspects: social security 、 daily care and rehabilitation, education and employment,social participation. It aims to understand the connotation of the rights and interests of disabled people in China. Currently, the law on the protection of the disabled refers to the rights and interests of disability trust only in article 49 and article 65,( Both of these are general terms that point out that the type of disabled persons and the rights of persons with disabilities should be punished by relevant laws and administrative punishments.) Therefore, there is too little content in the law, no system of regulations, no specific enforceable rules. The analysis of the connotation of the disability rights is helpful to supplement the legislation system and promote the whole development of the whole industry.

\section{Acknowledgement}

It's my pleasure to publish my paper on such a authority platform, thanks a lot to my school for the opportunity. The article relies on the subjects of Research on the teaching methods of law and reformation of quality education in Universities of technology (2014107) and Cultivation of Masters' Theses of Wuhan University of Technology (2016-YS-096), I really feel grateful to my task group members provided effective research cases and many practical data to support this paper's idea.Finally I would like to express my great appreciate to my mentor Li Mu's rigorous guidance, I will try my best for the further exploration .

\section{References}

[1] Fan L. L. \& Zhang Q. Q. Reflections on disability trust services from the perspective of the disability trust service model[J]. China Social Welfare (Theories), 2012 (3): 35.

[2] Guiding Notice on Accelerating Construction of the Social Security System and the Service System[J].Disability in China, 2010, (4): 5.

[3] Xiang Zicheng.Chinese people with disabilities protect the history of legal issues[D].Beijing: China university of political science and law.2004. 